\title{
Melatonin, the Hormone of Darkness: From Sleep Promotion to Ebola Treatment
}

Alina Masters-Israilov ${ }^{1}$, Seithikurippu R. Pandi-Perumal ${ }^{2}$, Azizi Seixas ${ }^{2}$, Girardin Jean-Louis ${ }^{2}$, and Samy I. McFarlane ${ }^{1^{*}}$

${ }^{1}$ Division of Endocrinology, Department of Medicine, SUNY Downstate Medical Center, 11203 Brooklyn, NY, USA

${ }^{2}$ Center for Healthful Behavior Change, Division of Health and Behavior, Department of Population Health, New York University School of Medicine, 227 East 30 th St, 10016 New York, NY, USA

"Corresponding author: Samy I. McFarlane, MD, MPH, MBA Professor of Medicine and Endocrinology, Department of Medicine Box 50 SUNY Downstate, 450 Clarkson Ave, Brooklyn, New York 11203, USA, Tel: 718270 3711; Fax: 718270 6358; E-mail: smcfarlane@downstate.edu

Rec date: Oct 24, 2014, Acc date: Nov 12, 2014, Pub date: Nov 20, 2014

Copyright: ( 2014 Masters A, et al. This is an open-access article distributed under the terms of the Creative Commons Attribution License, which permits unrestricted use, distribution, and reproduction in any medium, provided the original author and source are credited.

\begin{abstract}
Melatonin is a hormone secreted by the enigmatic pineal gland in response to darkness, hence the name hormone of darkness. It has generated a great deal of interest as a therapeutic modality for various diseases particularly sleep disorders. This pleiotropic molecule has anti-inflammatory, antioxidant and anticoagulopathic properties in addition to its endothelial protective effects. In this article we discuss melatonin secretion and mechanisms of action as well as therapeutic rationale. We also highlight the potential utility of melatonin in the deadly modern-day Ebola epidemic.
\end{abstract}

Keywords: Ebola; Human; Jetlag; Melatonin; Pineal; Sleep

\section{Introduction}

Shaped like a pinecone, the enigmatic pineal gland that is deeply seated in the brain has ignited the imagination of scholars and philosophers as well as spirituals from various cultures throughout generations and has been dubbed the "third eye" and "the seat of the soul" by René Descartes and was conceptualized as a 'tranquilizing organ' [1,2]. Interestingly, investigators suggested the pineal gland, and its hormone product melatonin, to be possibly associated with longevity $[3,4]$ and that pineal gland dysfunction and eventual failure is what initiates the aging process [5]. The first evidence that the pineal gland secretes a biologically active compound, now known as melatonin, was demonstrated by the ability of the pineal tissue extracts from bovine sources to alter melanin pigmentation in frogs, causing melanin aggregation, giving rise to the name melatonin [6,7]. These findings have led to the attempts of using melatonin as a treatment for vitiligo, which has proven to be largely ineffective. However, this research had led to the incidental discovery of the sleep-promoting effects of melatonin $[8,9]$.

\section{Melatonin Synthesis, Storage and Release}

Melatonin is the only known hormone synthesized by the pineal gland and is released in response to darkness hence the name, "hormone of darkness" [10]. Melatonin provides a circadian and seasonal signal to the organisms in vertebrates. Melatonin is produced from serotonin (made from tryptophan), through a cascade of enzymatic reactions (Figure 1). The last two steps in the pathway include the conversion of serotonin to $\mathrm{N}$-acetylserotonin (NAS) catalyzed by the enzyme arylalkylamine $\mathrm{N}$ acetyltransferase (AANAT) followed by the conversion of $\mathrm{N}$-acetylserotonin to melatonin catalyzed by the enzyme hydroxyl-indole-O-methyltransferase (HIOMT) [8].

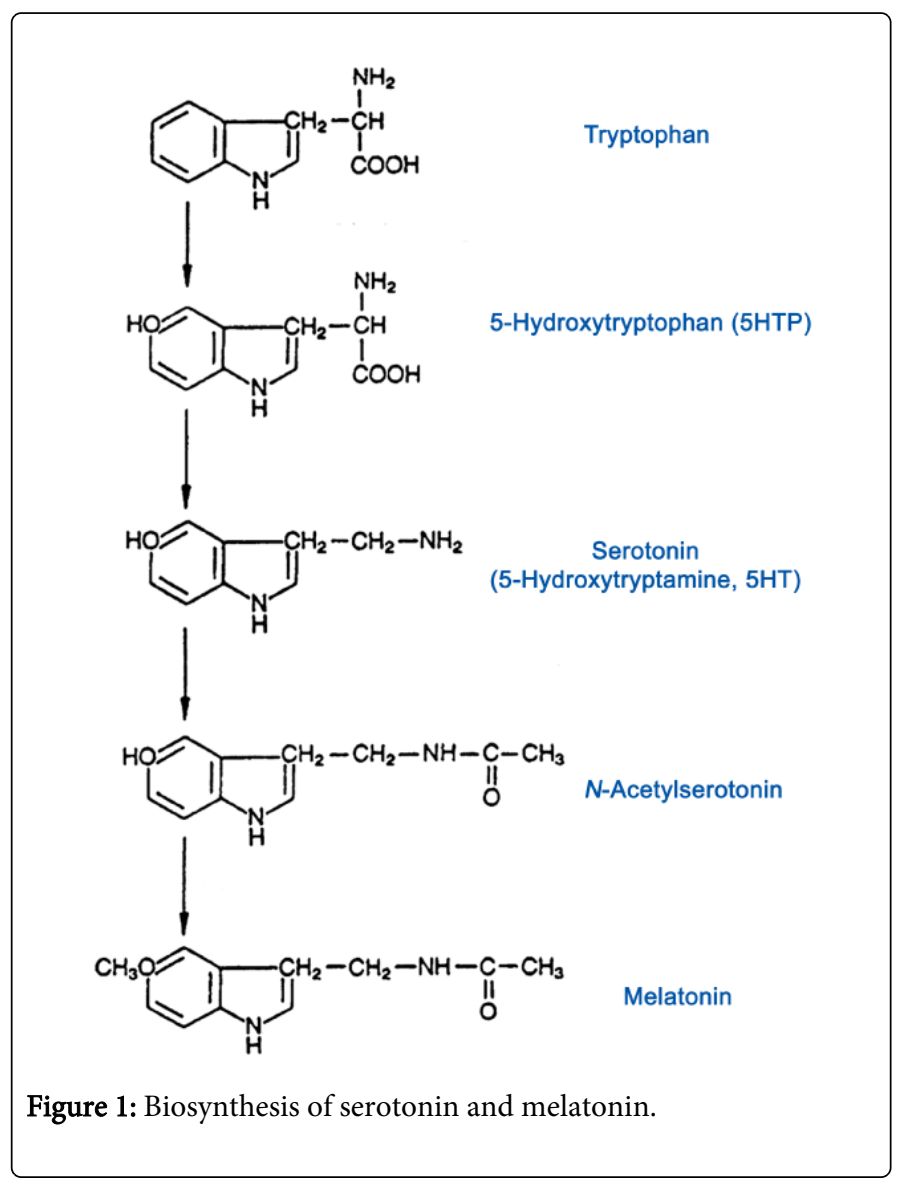

The pineal gland receives input from postganglionic fibers, leading to the release of noradrenaline and increased production of cyclic AMP, thus activating the enzyme AANAT, mentioned above, which is critical to the production of melatonin. The neurohormone melatonin is not stored in the pineal gland but rather is released into the bloodstream and can penetrate all body tissues [11] . It is important to 
note that "darkness" stimulates the pineal gland to secrete melatonin whereas exposure to light inhibits this mechanism [12].

Interestingly, the pineal gland, while embryologically part of the brain, is located outside the blood brain barrier and loses it connections with the central nervous system, having sympathetic innervation as its main source [7]. This perhaps accounts for the ability of the pineal gland to have a large uptake of tryptophan leading to a high melatonin production and secretion in response to darkness. This process also offers relative protection from premature enzymatic degradation which leads to a 10-20 fold increase in plasma melatonin levels that easily diffuses through cell membranes and crosses the blood brain barrier (BBB) $[7,13]$.

\section{Mechanisms of Action of Melatonin and Therapeutic Rationale}

With the increasing prevalence of sleep disorders associated with the epidemic of obesity, there has been a great deal of renewed interest in melatonin, its mechanism of action and its therapeutic effects. Sleep disorders, regardless of the etiology, are becoming frequently encountered by physicians and other health care providers. According to data from the Center for Disease Control (CDC), up to about 70 million Americans suffer from chronic sleep problems [14], which are generally associated with obesity, diabetes, hypertension and increased cardiovascular risk. While increasingly common in the general population coupled with obesity, sleep disorders are disproportionately severe and associated with increased cardiovascular risk among minority populations $[15,16]$. Sleep disorders are also commonly associated with other comorbidities as well including dementias, chronic pain, mental illness and gastrointestinal disorders [17]. Unfortunately, irrespective of the high prevalence and the serious health consequences, sleep disorders often go undiagnosed and largely undertreated [18]. It is therefore critical to properly diagnose and treat certain types of circadian rhythm sleep disorders such as advanced sleep phase syndrome (ASPS), shift-work sleep disorder, and jetlag $[19,20]$.

Although melatonin has effects on various cells in the human body [21], its sleep-promoting actions are mostly caused by its feedback to the suprachiasmatic nucleus (SCN; the master clock), specifically on the melatonin receptors (MT1 and MT2) [22]. By working on the SCN, melatonin helps to synchronize the circadian rhythm by affecting both the phase and amplitude of the rhythm [23,24]. It is proposed that neuronal firing is suppressed through MT1 receptors whereas MT2 receptors are responsible for phase shifting [23]. Thus, therapy with melatonin and related compounds has been often investigated and is a topic of interest for scholarly research.

Melatonin is sometimes prescribed to patients with sleep disturbances and has been shown to be effective in helping to treat certain sleep disorders such as jet lag $[19,20]$ and insomnia in the elderly [25]. In a meta-analysis study performed by Brzezinski, et al. in 2005 that included 15 studies of patients with only insomnia, melatonin treatment was shown to significantly reduce sleep onset latency, increase sleep efficiency and increase sleep duration [26]. Additionally, in a recent meta-analysis performed by Ferracioli-Oda, et al., (2013), melatonin was again found to significantly reduce sleep onset latency and increase total sleep time, when compared to placebo [27]. There were also clinical trials involving elderly insomniacs and patients with Alzheimer's disease who were suffering from sleep disturbances and showed improvement with exogenous melatonin [8].

\section{Administration and Safety Profile of Melatonin}

With regards to the actual administration of melatonin, it has been shown that the timing of melatonin administration, and not so much the actual dosage, is crucial in producing the best results; this is secondary to the normal physiologic function of the circadian rhythm [11]. For example, it was found that when melatonin was administered at bedtime as a "sleeping pill", it was not effective unless high doses were used $[11,28]$; however, when small doses of melatonin were administered to patients about 2 to 4 hours before bedtime, it was shown to be effective in decreasing sleep latency [29].

The side effect profile of melatonin therapy is quite reassuring and is largely superior to other sleep-inducing agents. For example, melatonin therapy does not cause withdrawal or dependence symptoms unlike benzodiazepines (BZDs) and z-drugs such as Zolpidem [23]. Some of potential harmful effects of exogenous melatonin therapy include immunomodulatory effects which confers the risk of worsening certain rheumatologic condition such as rheumatoid arthritis [30]. It might also result in amenorrhea when used in large doses, which is likely due to suppression of gonadotropin-releasing hormone $(\mathrm{GnRH})$ [31]. However, this effect is readily reversible with cessation of the medication.

\section{Role of Melatonin-Related Formulations}

Starting in 2005, several melatonin-related compounds were introduced including Ramelteon that is an agonist of MT1 and MT2 receptors with a longer half-life compared to melatonin [23]. This medication was approved in the USA by the FDA in 2005 as a treatment for insomnia [32]. It has been shown to have a much greater affinity to the MT1 and MT2 receptors when compared to melatonin itself [33]. A randomized controlled study performed by Erman, et al. found that Ramelteon is effective in decreasing the latency period to persistent sleep in various dosages [34]. Like melatonin therapy, Ramelteon was not shown to be associated with hangover effects or withdrawal symptoms [35].

Another interesting agent that has been recently FDA approved is Agomelatine. Besides its actions as an agonist on MT1 and MT2 receptors, this medication has the additional advantage of being an antagonist on the 5-HT2c serotonin receptor [36]. Aside from its potent antidepressive effects, this drug promotes sleep, an advantage that is lacking in most antidepressive agents. In fact, many antidepressants that are currently available can actually worsen sleep, instead of benefit it $[23,37]$.

One intriguing question that has arisen over the years is how blindness affects the circadian rhythm since input from the retina is compromised. Although a study performed by Czeisler, et al. in 1995 showed that some blind individuals, with no conscious perception of light, were still able to inhibit melatonin secretion when exposed to light [38], disruption of the sleep-wake cycle in blind individuals remains a target for investigation. Fortunately, based on the results of two published trials, a new agent Tasimelteon, was approved in 2014 for the treatment of a condition known as "non-24 hour" sleep disorder in blind patients [39]. This drug, another MT1 and MT2 receptor agonist, was shown to be superior when compared to placebo in facilitating entrainment of the circadian rhythm as well as the increasing night-time sleep in studied "non 24-hour" blind patients [40]. 


\section{Melatonin as a Possible Therapeutic Option for Ebola virus}

Melatonin, a versatile and pluripotent molecule, has been shown to have several beneficial effects above and beyond its highly celebrated property of sleep promotion (Figure 2).

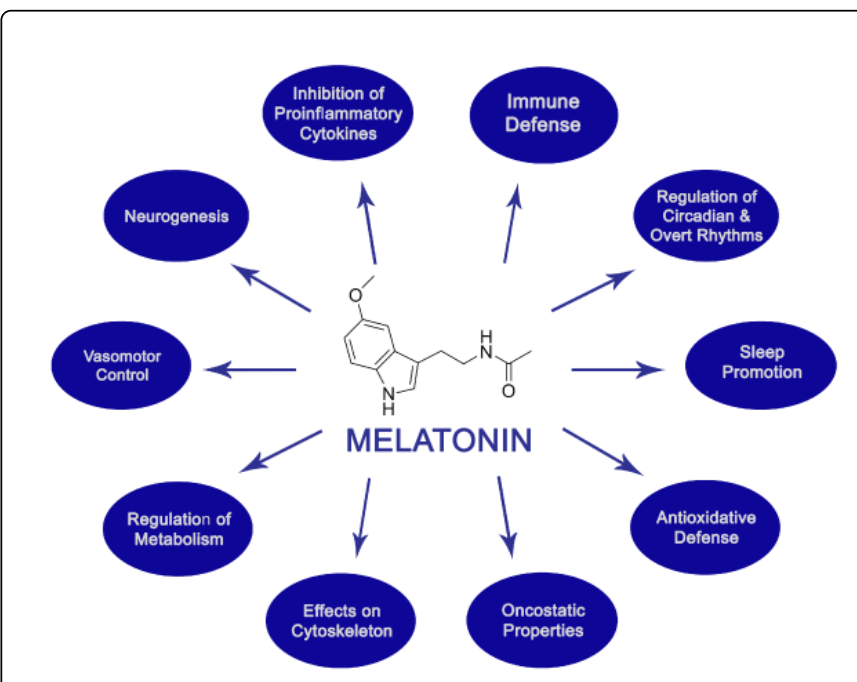

Figure 2: The pleiotropy of melatonin.

While melatonin has been shown to exhibit protective effects against certain neurodegenerative disorders such as Alzheimer's disease, Parkinson's disease $[3,41,42]$ and sundowning syndrome $[43,44]$, perhaps the most exciting of these pleotropic effects include anti-inflammatory, antioxidant, anticoagulopathic as well as endothelial-protective properties [45-48]. This has led to an exciting hypothesis by Dun-Xian Tan, et al. from the University of Texas in a recently published article highlighting these various beneficial effects of melatonin and proposing it as potential treatment for Ebola [49], a highly dreaded modern-day epidemic that has claimed over 4,500 lives thus far without a glimpse of hope for an effective therapeutic strategy in sight.

The pathogenetic mechanisms of Ebola virus infection, as eloquently outlined by Tan, et al., (2014) which include inflammation, coagulopathy, as well as endothelial disruption. These mechanisms are quite similar to the pathogenetic processes observed in septic shock albeit due to different offending agents, viral vs. bacterial [49]. While melatonin possesses pro- and anti-inflammatory properties, these contradictory characteristics reflect more anti-inflammatory benefits in advanced stages of inflammation [46]. Melatonin also has a favorable effect on coagulopathy, as demonstrated in a placebocontrolled study where a single dose of oral melatonin lowered plasma levels of procoagulant factors 60 minutes post-administration [48]. Accumulating evidence also indicates that melatonin ameliorates vascular endothelial dysfunction in several conditions such as hypertension, atherosclerosis, diabetes, reperfusion injury and nicotine-induced vasculopathy [47]. In a study involving high fat-fed rabbits, melatonin was shown to improve vascular endothelial function and inflammation and to inhibit the progression of atherosclerosis [45]. Furthermore, evidence exists indicating possible direct anti-viral effects of melatonin $[49,50]$. This has been suggested in a single-blinded, randomized study comparing acyclovir vs. melatonin added to a mixture of magnesium, phosphate, and fatty acids extracted from an Aspergillus species with known anti-viral properties in the treatment of patients with Herpes. The melatonin group was superior to the Acyclovir group in the regression of Herpes symptoms after 7 days of administration [51]. Collectively, this wide range of melatonin effects makes this pluripotent molecule an attractive therapeutic choice for Ebola virus, addressing the major pathogenetic pathways of this devastating illness, as proposed by Tan, et al. [49]. Although we believe that melatonin is unlikely to eradicate the virus or curb its proliferation, the authors of this commentary are in support of this approach given the current lack of effective therapeutic alternatives as well as the highly favorable safety profile of melatonin.

\section{Conclusion}

Over the decades, melatonin, an ancient, ubiquitous, and a pleiotropic molecule, which was frequently used as a popular supplement by the general public and had many media hypes and frenzy as well as cult status with unjustified therapeutic claims often resulted in tight scrutiny [52]. For example, melatonin was known as the Dracula hormone, Princess Diana drug, the sleep hormone, chemical expression of darkness, the hormone of darkness, nature's sleeping pill, universal panacea, miracle hormone, and the elixir of life. Nevertheless, substantial research over the years in many facets of melatonin has demystified the potentials roles of melatonin, thereby exceeding the expectations in terms of protecting human health. This has resulted in several melatonin-related compounds being approved by the U.S. Food and Drug Administration and used in the management of common disorders such as jet lag. Whether or not melatonin will be proven to be effective in combating the Ebola epidemic, it remains to be seen and most likely to be a rich field of scientific enquiry.

\section{Acknowledgements and Funding}

The authors would like to thank the anonymous reviewers for their helpful and constructive comments greatly contributed to improving the final version of the paper. They would also like to thank the Editor for his generous comments and support during the review process.

This work is supported by NIH grant R01MD004113 to GJL. However, the funders had no role in study design, data collection and analysis, decision to publish, or preparation of the manuscript.

\section{Competing Interests}

The authors declare no competing interests.

\section{References}

1. Booth FM (1987) The human pineal gland: a review of the "third eye" and the effect of light. Aust N Z J Ophthalmol 15: 329-336.

2. Romijn HJ (1978) The pineal, a tranquillizing organ? Life Sci 23: 2257-2273.

3. Srinivasan V, Cardinali DP, Srinivasan US, Kaur C, Brown GM, et al. (2011) Therapeutic potential of melatonin and its analogs in Parkinson's disease: focus on sleep and neuroprotection. Ther Adv Neurol Disord 4: 297-317.

4. Oaknin-Bendahan S, Anis Y, Nir I, Zisapel N (1995) Effects of long-term administration of melatonin and a putative antagonist on the ageing rat. Neuroreport 6: 785-788. 
5. Rozencwaig R, Grad BR, Ochoa J (1987) The role of melatonin and serotonin in aging. Med Hypotheses 23: 337-352.

6. McCord C, Allen FP (1917). Evidences associating pineal gland function of alterations in pigmentation. SO J Exptl Zool 23: 207.

7. Wurtman R. Physiology and Clinical Use of Melatonin, (http:// wurtmanlab.mit.edu/static/pdf/1050.pdf. (accessed on Oct 10, 2014).

8. Pandi-Perumal SR, Zisapel N, Srinivasan V, Cardinali DP (2005) Melatonin and sleep in aging population. Exp Gerontol 40: 911-925.

9. Lerner AB, Case JD (1960) Melatonin. Fed.Proc 19: 590-592.

10. Srinivasan V, Spence WD, Pandi-Perumal SR, Zakharia R, Bhatnagar KP et al. (2009) Melatonin and human reproduction: shedding light on the darkness hormone. Gynecol Endocrinol 25: 779-785.

11. Luboshizsky R, Lavie P (1998) Sleep-inducing effects of exogenous melatonin administration. Sleep Med Rev 2: 191-202.

12. Hardeland R (2013) Chronobiology of Melatonin beyond the Feedback to the Suprachiasmatic Nucleus-Consequences to Melatonin Dysfunction. Int J Mol Sci 14: 5817-5841.

13. Wurtman RJ, Axelrod J, Potter LT (1964) The Uptake of H3-Melatonin in Endocrine and Nervous Tissues and the Effects of Constant Light Exposure. $\mathrm{j}$ pharmacol exp ther 143: 314-318.

14. In: Colten HR, Altevogt BM (2006) eds. Sleep Disorders and Sleep Deprivation: An Unmet Public Health Problem. Washington (DC).

15. Donat M, Brown C, Williams N, Pandey A, Racine C et al. (2013) Linking sleep duration and obesity among black and white US adults. Clin Pract (Lond) 10:5

16. Zizi F, Pandey A, Murrray-Bachmann R, Vincent M, McFarlane S, et al. (2012) Race/ethnicity, sleep duration, and diabetes mellitus: analysis of the National Health Interview Survey. Am J Med 125: 162-167.

17. Skaer TL, Sclar DA (2010) Economic implications of sleep disorders. Pharmacoeconomics 28: 1015-1023.

18. Hossain JL, Shapiro CM (2002) The prevalence, cost implications, and management of sleep disorders: an overview. Sleep Breath 6: 85-102.

19. Brown GM, Pandi-Perumal SR, Trakht I, Cardinali DP (2009) Melatonin and its relevance to jet lag. Travel Med Infect Dis 7: 69-81.

20. Herxheimer A, Petrie KJ (2001). Melatonin for preventing and treating jet lag. Cochrane Database Syst Rev. CD001520.

21. Dubocovich ML, Markowska M (2005) Functional MT1 and MT2 melatonin receptors in mammals. Endocrine 27: 101-110.

22. Srinivasan V, Pandi-Perumal SR, Trahkt I, Spence DW, Poeggeler B, et al. (2009) Melatonin and melatonergic drugs on sleep: possible mechanisms of action. Int J Neurosci 119: 821-846.

23. Hardeland R, Poeggeler B, Srinivasan V, Trakht I, Pandi-Perumal SR, et al. (2008) Melatonergic drugs in clinical practice. Arzneimittelforschung 58: 1-10.

24. Pévet P, Bothorel B, Slotten H, Saboureau M (2002) The chronobiotic properties of melatonin. Cell Tissue Res 309: 183-191.

25. Haimov I, Lavie P, Laudon M, Herer P, Vigder C, et al. (1995) Melatonin replacement therapy of elderly insomniacs. Sleep 18: 598-603.

26. Brzezinski A, Vangel MG, Wurtman RJ, Norrie G, Zhdanova I, et al. (2005) Effects of exogenous melatonin on sleep: a meta-analysis. Sleep Med Rev 9: 41-50.

27. Ferracioli-Oda E, Qawasmi A, Bloch MH (2013) Meta-analysis: melatonin for the treatment of primary sleep disorders. PLoS One 8: e63773.

28. Cramer H, Rudolph J, Consbruch U, Kendel K (1974) On the effects of melatonin on sleep and behavior in man. Adv Biochem Psychopharmacol 11: 187-191.

29. Zhdanova IV, Wurtman RJ, Morabito C, Piotrovska VR, Lynch HJ (1996) Effects of low oral doses of melatonin, given 2-4 hours before habitual bedtime, on sleep in normal young humans. Sleep 19: 423-431.

30. Maestroni GJ, Cardinali DP, Esquifino AI, Pandi-Perumal SR (2005) Does melatonin play a disease-promoting role in rheumatoid arthritis? J Neuroimmunol 158: 106-111.
31. Pandi-Perumal SR, Srinivasan V, Maestroni GJ, Cardinali DP, Poeggeler B, et al. (2006) Melatonin: Nature's most versatile biological signal? FEBS J 273: 2813-2838.

32. Wurtman R (2006) Ramelteon: a novel treatment for the treatment of insomnia. Expert Rev Neurother 6: 957-964.

33. Kato K, Hirai K, Nishiyama K, Uchikawa O, Fukatsu K, et al. (2005) Neurochemical properties of ramelteon (TAK-375), a selective MT1/MT2 receptor agonist. Neuropharmacology 48: 301-310.

34. Erman M, Seiden D, Zammit G, Sainati S, Zhang J (2006) An efficacy, safety, and dose-response study of Ramelteon in patients with chronic primary insomnia. Sleep Med 7: 17-24.

35. Pandi-Perumal SR, Srinivasan V, Spence DW, Moscovitch A, Hardeland $\mathrm{R}$, et al. (2009) Ramelteon: a review of its therapeutic potential in sleep disorders. Adv Ther 26: 613-626.

36. Pandi-Perumal SR, Srinivasan V, Cardinali DP, Monti MJ (2006) Could agomelatine be the ideal antidepressant? Expert Rev Neurother 6: 1595-1608.

37. Lam RW (2006) Sleep disturbances and depression: a challenge for antidepressants. Int Clin Psychopharmacol 21 Suppl 1: S25-29.

38. Czeisler CA, Shanahan TL, Klerman EB, Martens H, Brotman DJ, et al. (1995) Suppression of melatonin secretion in some blind patients by exposure to bright light. $\mathrm{N}$ Engl J Med 332: 6-11.

39. Johnsa J, Neville MW (2014) Tasimelteon: A Melatonin Receptor Agonist for Non-24 Sleep-Wake Disorder. Ann Pharmacother.

40. Lockley SMD, Torres R, Lavedan C, Licamele LM (2013). Polymeropoulos Tasimelteon treatment entrains the circadian clock and demonstrates significant benefit on sleep and wake parameters in totally blind individuals with non-24 hour circadian rhythms. Sleep Medicine 14: 178.

41. Pandi-Perumal SR, BaHammam AS, Brown GM, Spence DW, Bharti VK, et al. (2013) Melatonin antioxidative defense: therapeutical implications for aging and neurodegenerative processes. Neurotox Res 23: 267-300.

42. Srinivasan V, Pandi-Perumal SR, Cardinali DP, Poeggeler B, Hardeland $\mathrm{R}$ (2006) Melatonin in Alzheimer's disease and other neurodegenerative disorders. Behav Brain Funct 2: 15.

43. Bedrosian TA, Nelson RJ (2013) Sundowning syndrome in aging and dementia: research in mouse models. Exp Neurol 243: 67-73.

44. de Jonghe A, Korevaar JC, van Munster BC, de Rooij SE (2010) Effectiveness of melatonin treatment on circadian rhythm disturbances in dementia. Are there implications for delirium? A systematic review. Int J Geriatr Psychiatry 25: 1201-1208.

45. Hu ZP, Fang XL, Fang N, Wang XB, Qian HY, et al. (2013) Melatonin ameliorates vascular endothelial dysfunction, inflammation, and atherosclerosis by suppressing the TLR4/NF-Î०B system in high-fat-fed rabbits. J Pineal Res 55: 388-398.

46. Radogna F, Diederich M, Ghibelli L (2010) Melatonin: a pleiotropic molecule regulating inflammation. Biochem Pharmacol 80: 1844-1852.

47. Rodella LF, Favero G, Foglio E, Rossini C, Castrezzati S, et al. (2013) Vascular endothelial cells and dysfunctions: role of melatonin. Front Biosci (Elite Ed) 5: 119-129.

48. Wirtz PH, Spillmann M, Bärtschi C, Ehlert U, von Känel R (2008) Oral melatonin reduces blood coagulation activity: a placebo-controlled study in healthy young men. J Pineal Res 44: 127-133.

49. Tan DX, Korkmaz A, Reiter RJ, Manchester LC (2014) Ebola virus disease: potential use of melatonin as a treatment. J Pineal Res 57: 381-384.

50. Boga JA, Coto-Montes A, Rosales-Corral SA, Tan DX, Reiter RJ (2012) Beneficial actions of melatonin in the management of viral infections: a new use for this "molecular handyman"? Rev Med Virol 22: 323-338.

51. Nunes Oda S, Pereira Rde S (2008) Regression of herpes viral infection symptoms using melatonin and SB-73: comparison with Acyclovir. J Pineal Res 44: 373-378. 